\title{
Urinary growth hormone estimation in diagnosing severe growth hormone deficiency
}

\author{
P Pirazzoli, M Mandini, S Zucchini, S Gualandi, L Vignutelli, M Capelli, E Cacciari
}

\begin{abstract}
Urinary growth hormone was measured in 54 children with short stature who had growth hormone deficiency that was initially diagnosed pharmacologically (arginine and L-dopa) and physiologically (mean growth hormone concentration during sleep evaluated twice). Based on the growth hormone response to pharmacological tests the subjects were subdivided into three groups: group A, 20 subjects with normal response (peak concentration $>8 \mu \mathrm{g} / 1$ ); group $B, 20$ subjects with response between 4 and $8 \mu \mathrm{g} / 1$; and group C, 14 subjects with response < 4 $\mu g / 1$. In group A four subjects had an abnormally low nocturnal mean growth hormone concentration $(\leqslant 3.3 \mu \mathrm{g} / 1)$. In group C seven subjects had multiple pituitary hormone deficiency and abnormal magnetic resonance imaging. All subjects had urine collected from $8.00 \mathrm{pm}$ to 8.00 am for 4-5 consecutive nights.
\end{abstract}

A positive correlation was found between serum nocturnal mean growth hormone values and urinary growth hormone in all subjects. Mean (SD) concentrations of urinary growth hormone were similar in groups $A$ (18.0 (9.5) $\mathrm{ng} / \mathrm{g}$ creatinine) and $B$ (13.6 (5.9) ng/g creatinine), but significantly higher than that of group C (3.4 (3.7) $\mathrm{ng} / \mathrm{g}$ creatinine). Considering as abnormal urinary growth hormones below the lower limit of the range in group $A$, specificity and sensitivity of urinary growth hormone was $100 \%$ and $35 \%$ respectively. Sensitivity for groups $B$ and C were $5 \%$ and $78 \%$ respectively. When considering only the subjects of group C with pathological magnetic resonance findings, sensitivity increased to $100 \%$. In the four subjects of group $A$ with mean growth hormone concentration $\leqslant 3.3 \mu \mathrm{g} / \mathrm{l}$, specificity decreased to $80 \%$.

It is concluded that urinary growth hormone assay is characterised by a sensitivity too low to be regarded as improving the traditional diagnostic approach to define growth hormone deficiency, unless it is used to identify subjects with the most severe deficiencies.

(Arch Dis Child 1996;75:228-231)

Keywords: dwarfism, urinary growth hormone.

Correspondence to: Professor Emanuele Cacciari 1 st Paediatric Clinic, via Massarenti 11, 40138 Bologna, Italy.

Accepted 24 April 1996
The best diagnostic approach to growth hormone deficiency is currently debatable. Traditional protocols (pharmacological stimu- lation tests) and more recent ones (evaluation of spontaneous secretion) are characterised by poor compliance and significant costs. Moreover, the results obtained, affected by great variability, may not represent a reliable tool for predicting outcome to treatment. ${ }^{1-6}$ Diagnosis may benefit from evaluating growth hormone excretion in urine ${ }^{7-10}$ : but studies so far published on urinary growth hormone have obtained conflicting results. ${ }^{9-12}$ Diagnostic protocols based on serum growth hormone assays might best be limited to subjects in whom this inexpensive and simple preliminary screening has identified a reduced urinary growth hormone excretion.

Our aim was to validate possible diagnostic applications of urinary growth hormone in clinical practice in a group of patients of short stature in whom growth hormone secretion had been measured by traditional methods.

\section{Patients and methods}

We examined 54 children with short stature (height $<5$ th centile at diagnosis); there were 32 males and 22 females ranging in age from 5.6 to 16.8 years. Thirty four subjects had been diagnosed as growth hormone deficient on the basis of growth hormone response after arginine and L-dopa tests (growth hormone peak $<8 \mu \mathrm{g} / 1$ in both tests) and had been treated with growth hormone for various periods of time; the remainder were patients initially investigated for short stature whose growth hormone was $>8 \mu \mathrm{g} / 1$ after pharmacological tests. Patients were subdivided as follows: group A included 20 children (12 prepubertal, eight pubertal with Tanner pubertal stages 2-3) with normal growth hormone response to pharmacological tests; group B included 20 children (19 prepubertal, one pubertal with Tanner pubertal stage 2) with growth hormone response between 4 and 8 $\mu \mathrm{g} / \mathrm{l}$; and group $\mathrm{C}$ included 14 children with a growth hormone peak $<4 \mu \mathrm{g} / \mathrm{l}$. The latter included seven prepubertal patients with idiopathic growth hormone deficiency (six prepubertal, one pubertal with Tanner pubertal stage 2), four male patients with congenital multiple pituitary hormone deficiency (all on replacement therapy with testosterone enanthate), and three prepubertal patients with acquired multiple deficiency due to cerebral tumour treated with surgery or radiation.

All patients, before the start of the present study, also had an evaluation of spontaneous nocturnal mean growth hormone concentration performed twice with a continuous withdrawal pump. Four children in group A 
had an abnormal result (mean growth hormone concentration as mean of two nights $\leqslant 3.3 \mu \mathrm{g} / \mathrm{l})$. We chose this threshold as we found no value above this level in a group of 51 previously examined children with short stature who had severe growth hormone deficiency, defined by a peak concentration $<4$ $\mu \mathrm{g} / 1$ both after two pharmacological tests and two sleep tests. The latter were performed from $8.00 \mathrm{pm}$ to $8.00 \mathrm{am}$, with samples collected every 20 minutes.

Growth hormone was assayed on serum using the immunofluorometric assay method (Cyberfluor Inc, Toronto, Canada). Intra-assay and interassay coefficients of variation were $7.8 \%$ and $6.3 \%$ respectively at the concentrations of $1.2 \mu \mathrm{g} / 1$ and $10.7 \%$ and $9.9 \%$ respectively at $12.5 \mu \mathrm{g} / \mathrm{l}$. Magnetic resonance imaging of the sellar area, performed on children in group B and C, showed morphological abnormalities, in the three subjects with secondary hypopituitarism, and those with multiple hormone deficiencies. In these four subjects the pathological findings included absent stalk with posterior pituitary ectopia and hypoplasia of the anterior lobe.

PROTOCOL

In all subjects previously treated with growth hormone, treatment was suspended for at least one month before the start of urine collection. All had urine collected, from $8.00 \mathrm{pm}$ to 8.00 am, for 4-5 subsequent nights (mean 4.2). The result was considered as mean of the values. For urine collection and storage we used polypropylene bottles and tubes. Before use, 10 drops of a $30 \%$ bovine serum albumin solution were added to each tube. Urine containers were kept in a refrigerator during the collection period and samples were centrifuged within two hours after the end of collection and immediately stored at $-20^{\circ} \mathrm{C}$ until assay. All samples were measured after a maximum period of four weeks in storage.

\section{ASSAY}

Urinary growth hormone assay was performed using an immunoradiometric assay kit provided by Merieux (Paris, France). The method is consistent with the direct evaluation of growth hormone without urine concentration or dialysis. At the concentrations of $6 \mu \mathrm{g} / 1$ and $20 \mu \mathrm{g} / 1$ intra-assay coefficients of variation were $14.2 \%$ and $5.4 \%$ respectively and interassay coefficients of variations were $16.3 \%$ and $8 \%$ respectively. Urinary growth hormone concentration was expressed as $\mathrm{ng} / \mathrm{g}$ of creatinine. In an attempt to minimise day to day variations of urinary growth hormone, we calculated for each subject the mean urinary growth hormone value of all collections.

\section{STATISTICS}

Statistical evaluation of the results obtained in the various groups was by Student's $t$ test. The coefficient of linear correlation was used to correlate nocturnal serum growth hormone values (mean of 2) and urinary growth hormone values (mean of 4 or 5). Urinary growth hormone diagnostic sensitivity was evaluated using the formula [a: $(a+c)] \%$, where a represents true positives and $c$ false negatives. Urinary growth hormone diagnostic specificity was evaluated using the formula $[d:(d+b)] \%$, where $d$ represents true negatives and $b$ false positives. In each subject the coefficients of variability of 'day to day' urinary growth hormone, growth hormone response to pharmacological tests, and mean growth hormone concentration were calculated with the formula [(A1-An):M]\%, where A1 and An are the limits of the range and $M$ the mean.

\section{Results}

Mean (SD) serum growth hormone concentration of group A (4.0 (1.4) $\mu \mathrm{g} / \mathrm{l})$ was significantly higher than that of group B (2.2 (0.8) $\mu \mathrm{g} / \mathrm{l} ; \mathrm{p}<0.0001)$ and of group C (1.2 (1.4) $\mu \mathrm{g} / \mathrm{l} ; \mathrm{p}<0.0001)$.

Urinary growth hormone concentrations found in each child are shown in fig 1. Mean concentrations of urinary growth hormone in groups A (18.0 (9.5) $\mathrm{ng} / \mathrm{g}$ creatinine) and B (13.6 (5.9) $\mathrm{ng} / \mathrm{g}$ creatinine) did not show significant differences, but were higher ( $p<0.0001$ and $\mathrm{p}<0.001$ respectively) than those of group C (3.4(3.7) $\mathrm{ng} / \mathrm{g}$ creatinine). As shown, there was a consistent overlap of urinary growth hormone values between the three groups of patients. There was a positive correlation between urinary growth hormone concentrations and mean nocturnal growth hormone $(r=0.45 ; p<0.0001)$ in all patients.

In group $\mathrm{A}$, mean urinary growth hormone was the same in prepubertal and pubertal children (13.2 (8.9) and 10.8 (9.6) ng/g creatinine respectively).

By arbitrarily considering as abnormal urinary growth hormones below the lower limit of the range in group A (4.7 ng/g creatinine) (fig 1 ), specificity (true negatives) was, of course, $100 \%$; sensitivity (true positives) was only $35 \%$ $(12 / 12+22)$ : in fact, as many as 22 children belonging to groups $B$ and $C$ had a value above $4.7 \mathrm{ng} / \mathrm{g}$ creatinine. For group B, sensitivity was $5 \%(1 / 1+19)$ : in fact only one patient (puber-

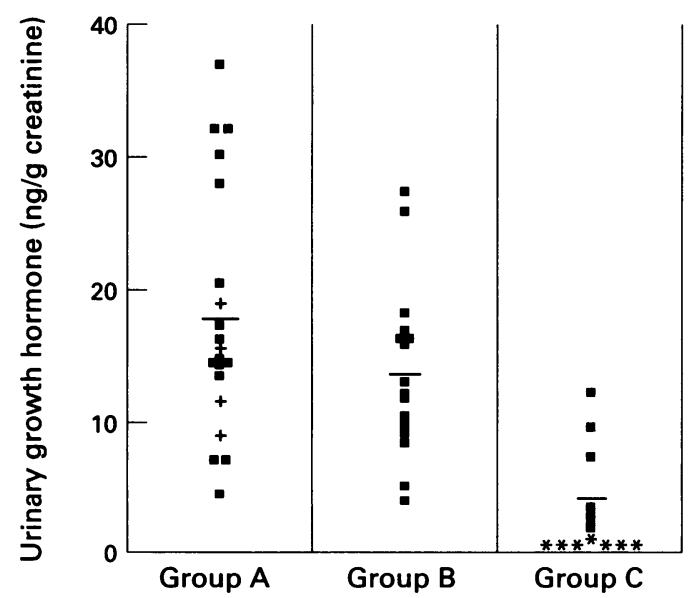

Figure 1 Urinary growth hormone concentrations of the subjects subdivided into three groups according to growth hormone response to pharmacological tests: response $>8$ $\mu g / l$ in group $A(+$ indicates the subjects with neurosecretory dysfunction); response between 4 and $8 \mu \mathrm{g} / \mathrm{l}$ in group $B$; response < $4 \mu \mathrm{g} / \mathrm{l}$ in group $C\left(^{*}\right.$ indicates the subjects with pathological magnetic resonance findings and multiple pituitary hormone deficiency). 
tal) in this group had a value below $4.7 \mathrm{ng} / \mathrm{g}$ creatinine. For group C, sensitivity was $78 \%$ $(11 / 11+3)$ : three subjects (two prepubertal and the pubertal subject) had a value above the threshold. If we considered only the patients with pathological magnetic resonance findings, specificity and sensitivity were $100 \%$, that is all the patients with multiple hormone deficiencies had an abnormal urinary growth hormone value. Finally, if we considered that four subjects (three prepubertal and one pubertal) of group A were affected by neurosecretory dysfunction (mean growth hormone concentration $\leqslant 3.3 \mu \mathrm{g} / \mathrm{l}$ ) (fig 1 ), specificity decreased from $100 \%$ to $80 \%(16 / 16+4)$.

The 'day to day' coefficient of variation of urinary growth hormone (138.4 (96.4)) was significantly higher $(p<0.0001)$ than that found both in the growth hormone responses after the pharmacological tests (51.5 (49.1)) and in the two sleep tests (30.4 (32.9)).

\section{Discussion}

We have shown that urinary growth hormone assay identifies only $35 \%$ of children diagnosed as growth hormone deficient by traditional tests (two pharmacological tests). These data not only confirm the overlap between the growth hormone deficient and the nondeficient subjects, ${ }^{9}$ but clearly underline that a diagnostic approach based on urinary growth hormone evaluation cannot distinguish (sensitivity $5 \%$ ) between those with mild deficiency (group B) and those without deficiency (group A) (fig 1). Urinary growth hormone in children with the most severe deficiency (group C) (fig 1), produces better results (sensitivity $78 \%$ ) but complete reliability (sensitivity and specificity of $100 \%$ ) was reached only in those with severe deficiency due to anatomical abnormalities of the hypothalamic-pituitary area.

Despite the fact that growth hormone secretion increases at puberty differently in boys from girls, ${ }^{13}$ as also recently described for urinary growth hormone in normal children, ${ }^{12}$ we adopted the same urinary growth hormone concentration for all patients for the following reasons: a common threshold is normally used when evaluating serum growth hormone concentrations during pharmacological and physiological tests; our pubertal children had values no higher than those who were prepubertal; and the relatively small number in our study sample did not allow further subdivision of patients. On the other hand, as with serum growth hormone, ${ }^{4}$ we found pubertal subjects both above and below the pathological threshold.

The diagnostic use of urinary growth hormone assay was initially suggested by reports of correlation between serum and urinary growth hormone, ${ }^{7} 10^{14}$ found both for spontaneous secretion and for the response to pharmacological tests. Moreover, Winer et al, ${ }^{15}$ Weissberger et $a l{ }^{16}$ and Girard et $a l^{17}$ described in both normal and pathological subjects discrepancies between serum and urinary growth hormone. We believe our results confirm the initial studies, as we found a positive correlation between serum and urinary growth hormone concentrations in the whole group of subjects. Furthermore, the low urinary growth hormone concentrations found in our patients with severe pituitary deficiency confirm that the amount of growth hormone excreted in urine has a direct relationship to the amount of hormone secreted by the pituitary. However, the overlap of urinary growth hormone values between growth hormone deficient and non-growth hormone deficient subjects that we found (fig 1) confirms ${ }^{9}$ the possibility that even minimal variations of the processes affecting growth hormone clearance (calculated between $0.003 \%$ and $0.025 \%{ }^{18}$ ) may invalidate urinary growth hormone evaluation as a marker of pituitary secretion. Despite the fact that pharmacological test responses do not necessarily reflect spontaneous secretion in any individual, ${ }^{19}{ }^{20}$ our groups of patients classified on the basis of pharmacological test response (A,B, and C) showed significantly different mean growth hormone concentrations. Although several investigations and also our study have described the correlation between serum and urinary assay, ${ }^{71014}$ urinary growth hormone evaluation found no difference between children in groups A and B. A deficient mean growth hormone concentration $(\leqslant 3.3 \mu \mathrm{g} / \mathrm{l})$ evaluated by serum assay justified growth hormone treatment of four subjects belonging to group $\mathrm{A}$, as they were classified as having 'neurosecretory dysfunction' ${ }^{20}$ However, that possibility was excluded by our urinary growth hormone assay.

The clinical usefulness of traditional diagnostic procedures is particularly affected by their limited reproducibility, possibly due to the fluctuating growth hormone secretion over time and the high variability of growth hormone responses to repeated tests. ${ }^{2-4}$ In this study, diagnostic discordances between serum and urinary assay may be partly explained by the variations of pituitary secretion that occurred in the period between the application of the various protocols. However, variability of 'day to day' excretion seems the only dimension predominantly influencing the validity of urinary growth hormone assay, as the coefficient of variation in our study was significantly higher than the already high value found in serum assays.

Despite this poor diagnostic value, urinary growth hormone assay might reasonably be used in qualitative investigations carried out on a wide number of subjects because of its low cost compared with the traditional assays and to the simple method of sampling collection. Using this approach Hashida $e t$ al, ${ }^{21}$ Quattrin et $a l^{22}$ and Ishikawa $e t a l^{3}$ studied variations in urinary growth hormone excretion from childhood to adult age and Khono et $a l^{24}$ described lower urinary growth hormone concentrations than those of the normal population in patients with Turner's syndrome.

We conclude that urinary growth hormone assay is characterised by a sensitivity too low to be considered as improving on the traditional diagnostic approaches to define growth hormone deficiency, except when used to identify patients with the most severe deficiencies. 
1 Zadik Z, Chalew SA, Gibuta Z, Kowarscki A. Reproducibility of growth hormone testing procedures: a comparison between 24-hour integrated concentration and pharmacological stimulation. $¥$ Clin Endocrinol Metab 1990; 71: 1127-30.

2 Tassoni P, Cacciari E, Cau M, et al. Variability of growth hormone response to pharmacological and sleep tests perhormone response to pharmacological and sleep tests per-
formed twice in short children. $尹$ Clin Endocrinol Metab 1990; 71: 230-4.

3 Cacciari E, Tassoni P, Parisi G, et al. Pitfalls in diagnosing impaired growth hormone (GH) secretion: retesting after replacement therapy of 63 patients defined as $\mathrm{GH}$ deficient. F Clin Endocrinol Metab 1992; 74: 1284-9.

4 Cacciari E, Tassoni P, Cicognani A, et al. Values and limits of pharmacological and physiological tests to diagnose growth hormone deficiency and predict therapy response: first and second retesting during replacement therapy of crinol Metab 1994; 79: 1663-9.

5 Donaldson DR, Hallowell JG, Pan F, Gifford RA, Moore WV. Growth hormone secretoy profiles: variation on consecutive nigths. $\mathcal{F}$ Pediatr 1989; 115: $51-6$.

6 Brook CD, Hindmarsh PC, Smith PJ. Is growth hormone deficiency a useful diagnosis? Acta Paediatr Scand 1987; 362 (suppl):70-5.

7 Hashida S, Ishikawa E, Kato Y. Human growth hormone (hGH) in urine and its correlation with serum hGH examined by highly sensitive sandwich enzyme immunoassay. Clin Chim Acta 1987; 162: 229-35.

8 Girard J, Erb T, Pampalone A. Growth hormone in urine. Horm Res 1987; 228: 71-80.

9 Albini CH, Sotos J, Sherman B, et al. Diagnostic significance of urinary growth hormone measurements in children with growth failure: correlation between serum and urine growth hormone. Pediatr Res 1991; 29: 619-22.

$10 \mathrm{Kalchi} \mathrm{K}$, Takuo I, Masafoshi $\mathrm{H}$, et al. Urinary excretion human growth hormone in children with short stature: correlation wth pituitary secretion of human growth hormone. f Pediatr 1992; 120: $233-7$.

11 Hourd P, Edwards R. Current methods for the measurement of growth hormone in urine. Clin Endocrinol (Oxf) 1994; 40: 155-70.

12 Léger J, Reverchon C, Porquet D, Noel M, Czernichow P. The wide variations in urinary excretion of human growth hormone in normal growing and growth hormonedeficient children limits its clinical usefulness. Horm Re 1995; 44: 57-63.
13 Rose SR, Municchi G, Barnes KM, et al. Spontaneous growth hormone secretion increases during puberty in normal girls and boys. $\mathcal{F}$ Clin Endocrinol Metab 1991; 73: 42835.

14 Crowne EC, Wallace WHB, Shalet SM, Addison GM, Price DA. Relationship between urinary and serum growth hormone and pubertal status. Arch Dis Child 1992; 67: 91-5.

15 Winer LM, Shaw MA, Bauman G. Urinary growth hormone excretion rates in normal and acromegalic man: a critical appraisal of its potential clinical utility. $\mathcal{F}$ Endocrinol Invest 1989; 12: 461-7.

16 Weissberger AJ, Ho KY, Stuart MC. Quantification of urinary growth hormone (GH) excretion by centrifugal ultrafiltration and radioimmunoassay: appraisal of the relationship between $24 \mathrm{~h}$ urinary $\mathrm{GH}$ and mean serum $\mathrm{GH}$ level in normal and abnormal states of $\mathrm{GH}$ secretion. Clin Endocrinol (Oxf) 1989; 30: 687-98.

17 Girard J, Celniker A, Price A, et al. Urinary measurement of growth hormone secretion. Acta Paediatr Scand 1990; 366 (suppl):149-54

18 Hattori N, Shimatsu A, Kato Y, et al. Urinary excretion of human growth hormone: daily variation and relationship with albumin and -microglobulin in urine. Acta Endocrino 1989; 121: 533-7.

19 Siegel SF, Becker DJ, Lee PA, Gutai JP, Foley TP, Drash AL. Comparison of physiologic and pharmacologic assessment of growth hormone secretion. Am 7 Dis Child 1984; 138: $540-3$.

20 Spiliotis BE, August GP, Hung W, Sonis W, Mendelson W, Bercu BB. Growth hormone neurosecretory disfunction. ҰAMA 1984; 251: 2223-30.

21 Hashida S, Ishikawa E, Nokajawa R, et al. Level of human growth hormone in urine determined by a kidney specific and sensitive sandwich immunoassasy. Analytical Letters 1986; 19: 625-38.

22 Quattrin T, Albini C, Vandlen RI, Mills BJ, MacGillvray MH. Quantitation of urinary somatomedin C and growth hormone in preterm and fullterm infants and normal children. $₹$ Clin Endocrinol Metab 1988; 66: 792-7.

23 Ishikawa E, Hashida S, Kato Y, Imura H. Sensitive enzyme immunoassay of human growth hormone for clinical immunoassay of human growth hormone for clin

24 Kohno H, Honda S. Low urinay growth hormone values in patients with Turner's syndrome. $f$ Clin Endocrinol Metab 1992; 74: 619-22. 